\title{
LAJU PERTUMBUHAN, LAJU KEMATIAN DAN EKSPLOITASI IKAN TONGKOL KOMO, Euthynnus affinis (Cantor 1849), DI PERAIRAN SAMUDERA HINDIA BARAT SUMATERA
}

\author{
GROWTH, MORTALITY AND EXPLOITATION RATES OF KAWAKAWA, \\ Euthynnus Affinis (Cantor 1849), IN INDIAN OCEAN WEST SUMATERA
}

\author{
Irwan Jatmiko $^{1}$, Ririk Kartika Sulistyaningsih ${ }^{1}$ dan Duto Nugroho ${ }^{2}$ \\ ${ }^{1}$ Peneliti pada Loka Penelitian Perikanan Tuna-Benoa \\ ${ }^{2}$ Peneliti Pada Pusat Penelitian Pengelolaan Perikanan dan Konservasi Sumber Daya Ikan \\ Teregistrasi I tanggal: 05 Februari 2014; Diterima setelah perbaikan tanggal: 25 Juli 2014; \\ Disetujui terbit tanggal: 05 Agustus 2014 \\ Email: irwan.jatmiko@gmail.com
}

\begin{abstract}
ABSTRAK
Tongkol komo (Euthynnus affinis Cantor, 1849) merupakan hasil tangkapan utama bagi nelayan pukat cincin di Samudera Hindia sebelah barat Sumatera. Penelitian ditujukan untuk memperoleh data dan informasi tentang estimasi laju pertumbuhan, laju kematian dan laju eksploitasi ikan tongkol komo. Analisis dilakukan berdasarkan himpunan data frekuensi panjang cagak sebanyak 1.325 ekor hasil tangkapan pukat cincin yang didaratkan di Pelabuhan Sibolga. Contoh ikan dikumpulkan secara bulanan dari bulan Juli 2012 hingga Februari 2013. Pendugaan parameter dilakukan menggunakan program FISAT II (FAO-ICLARM Stock Assessment Tools). Hasil kajian menunjukkan kisaran panjang cagak antara $30-60 \mathrm{~cm}$, panjang asimptotik $(L \infty)=63,5 \mathrm{~cm}$, laju pertumbuhan $(K)=0,63 /$ tahun dan umur teoritis pada saat panjang ke $0\left(t_{0}\right)=-0,21$ tahun. Estimasi laju kematian total tahunan $(Z)$ sebesar 2,40/tahun, laju kematian alami $(M)$ sebesar 1,07/tahun dan laju kematian akibat penangkapan $(F)$ sebesar 1,33/tahun. Perkiraan Laju eksploitasi $(E)=0,55$ mengindikasikan bahwa tingkat pemanfaatan berada pada tingkat yang moderat.
\end{abstract}

Kata Kunci: Pertumbuhan, kematian, eksploitasi, tongkol komo, Samudera Hindia Barat Sumatera

\section{ABSTRACT}

Kawakawa (Euthynnus affinis Cantor, 1849) is the one of the major catch of fishermen in the Indian Ocean west off Sumatera. This study was aimed to investigate data and information on growth, mortality and the exploitation rates of kawakawa. Analyses were carried out based on a number of 1,325 length frequency data from purse seine fishery landed in Sibolga Fishing Port. Monthly base data were collected from July 2012 to February 2013. The specimens ranged from 30 to $60 \mathrm{~cm} \mathrm{FL.} \mathrm{parameters} \mathrm{were} \mathrm{determined} \mathrm{through} \mathrm{a} \mathrm{package}$ program of FISAT II (FAO-ICLARM Stock Assessment Tools). The result showed that asymptotic length $(L \infty)$ were $63.5 \mathrm{cmFL}$, growth rates $(K) 0.63 / y$ r and estimated $t_{0}-0.21$ years. The annual instantaneous rate of total mortality $(Z)$ was $2.40 / y$ r, the natural mortality $(M)$ was 1.07/yr and the fishing mortality $(F)$ was 1.33/yr. The exploitation rate $(E=0.55)$ indicated that $E$. affinis was moderately exploited in the area.

Keywords: Growth, mortality, exploitation, kawakawa, Indian Ocean, West Sumatera

\section{PENDAHULUAN}

Indian Ocean Tuna Commission (IOTC) menyatakan terdapat enam spesies tuna neritik dan sheerfish di Samudera Hindia, yaitu: tongkol abu-abu (Thunnus tonggol), tongkol krai (Auxis thazard), tongkol lisong (Auxis rochei), tongkol komo (Euthynnus affinis), tenggiri (Scomberomorus commerson) dan tenggiri papan (Scomberomorus guttatus) (Herrera \& Pierre, 2009). Di Indonesia, keenam spesies ini ditangkap menggunakan pukat cincin, jaring insang hanyut, pancing ulur dan pancing tonda dengan daerah panangkapan terdapat di Samudera Hindia sebelah Barat Sumatera dan Selatan Jawa (Widodo et al., 2012).
Tongkol komo (Euthynnus affinis) merupakan salah satu spesies ikan epipelagic yang hidup di perairan hangat dengan kisaran suhu antara $18^{\circ}-29^{\circ} \mathrm{C}$. Distribusi spesies ini banyak ditemukan di perairan sekitar pulau dan kepulauan di Samudera Hindia dan Samudera Pasifik bagian Barat (Collette \& Nauen, 1983). Tingkah laku umumnya dicirikan beruaya dekat dengan pantai dan membentuk gerombolan besar dan sering bercampur dengan ikan dari famili Scombridae lainnya (DPI-NSW, 2010). Produksi ikan tongkol komo tahun 2001-2010 di Indonesia yang berasal dari Samudera Hindia merupakan bagian yang terbesar diantara jenis tuna neritik lainnya. Produksi total ikan tuna neritik pada kurun waktu tersebut mencapai 1.325.232 ton. Komposisi produksi tongkol 
komo paling besar yaitu $27 \%$ yang diikuti oleh tongkol krai dan tongkol lisong (25\%), tongkol abu-abu (24\%), tenggiri totol (18\%) dan tenggiri papan (6\%) (FAO, 2013).

Hasil tangkapan ikan tongkol komo di Indonesia sebagian besar merupakan hasil tangkapan sampingan dari pukat cincin. Target penangkapan pukat cincin adalah ikan cakalang, ikan tuna seperti tuna mata besar dan tuna sirip kuning (LPPT, 2013). Tujuan penelitian ini adalah untuk mengetahui parameter populasi ikan tongkol komo yang meliputi: umur dan pertumbuhan, parameter laju kematian (alami dan akibat penangkapan). Hasil penelitian ini diharapkan dapat memberikan kontribusi bagi pengelolaan dan pemanfaatan perikanan berdasarkan kaidah ilmiah dan tata kelola secara berkelanjutan.

\section{METODE}

Penelitian didasarkan pada data hasil pengumpulan contoh ikan tongkol komo (Euthynnus affinis) yang dikumpulkan dengan bantuan enumerator di Pelabuhan Perikanan Sibolga, Sumatera Utara. Contoh ikan sebanyak 1.325 ekor dikumpulkan dari hasil tangkapan kapal pukat cincin yang beroperasi di perairan Samudera Hindia Barat Sumatera dari bulan Juli 2012 hingga Februari 2013. Pengukuran panjang ikan dilakukan dengan mengukur panjang cagak (fork length) dengan ketelitian $1 \mathrm{~cm}$. Untuk keperluan analisis , data frekuensi panjang dikelompokan menurut kisaran panjang $2 \mathrm{~cm}$.

Parameter pertumbuhan ( $K$ dan $L \infty)$ dihitung dengan metoda Elefan I (Gayanilo et al., 2005) dan mengikuti persamaan pertumbuhan von Bertalanffy sebagai berikut:

$$
L t=L \infty\left(1-e^{\left[K\left(t-t_{O}\right)\right]}\right)
$$

$L t$ adalah panjang pada saat umur ke $t, L \infty$ adalah panjang asimptotik, $K$ adalah laju pertumbuhan dan $t_{0}$ adalah umur secara teori pada saat panjang ikan $0 \mathrm{~cm}$ (Sparre \& Venema, 1998). Program FiSAT II hanya menyajikan estimasi dari $L \infty$ dan $K$; untuk $t_{0}$ dihitung menggunakan rumus Pauly (1980) sebagai berikut:

$$
\log \left(-t_{0}\right)=-0,3922-0,2752 \log \operatorname{Lo}-1,038 \log K \ldots(2)
$$

Kurva tangkapan konversi panjang (length-converted catch curves) yang diperoleh dari frekuensi panjang dapat digunakan untuk menduga total kematian (Z) (Gayanilo et al., 2005). Mortalitas alami ( $M$ ) dihitung menggunakan rumus Pauly (Pauly, 1983):

$\begin{aligned} \log , M= & -0.0066-0.279 \log L \infty+0.6543 \log K+ \\ & 0.4634 T \ldots \ldots \ldots \ldots \ldots \ldots \ldots \ldots \ldots \ldots \ldots \ldots \ldots \ldots \ldots \ldots \ldots \ldots \ldots \ldots \ldots \ldots \ldots \ldots \ldots \ldots\end{aligned}$ dimana:

$T$ : suhu rata-rata tahunan pada habitat dari spesies $\left(28^{\circ}\right.$ C).
Perkiraan laju kematian total diturunkan melalui persamaan kurva hasil tangkapan (C) yang dilinierkan dengan selang waktu yang sama dimana koefisien kemiringan merupakan besaran laju kematian total $(Z)$ seperti dikemukakan Ricker (1975) dalam Sparre \& Venema (1999) sebagai berikut :

$\operatorname{LnC}(t, t+\Delta t)=g-Z * t$

$F$ adalah laju kematian akibat penangkapan yang dihitung mengikuti persamaan empiris hubungan antara laju kematian total merupakan penjumlahan kematian akibat penangkapan dan laju kematian alami atau mengikuti persamaan sebagai berikut:

$\mathrm{Z}=F+M$

Laju eksploitasi $(E)$ dihitung menggunakan rumus umum yang dikemukakan oleh Sparre \& Venema (1998) sebagai berikut:

$E=F / Z$

\section{HASIL DAN BAHASAN HASIL}

Penelitian ini dilakukan selama 8 bulan berturut-turut dari bulan Juli 2012 hingga Februari 2013. Sejumlah 1.325 spesimen tongkol komo telah diukur panjang cagaknya (fork length) dengan kisaran panjang 30 hingga $60 \mathrm{~cm}$ (Lampiran 1). Sebaran data ukuran panjang memperlihatkan bahwa rerata terendah $(36,8 \mathrm{~cm})$ terdapat pada bulan Nopember sedangkan tertinggi $(46,2 \mathrm{~cm})$ pada bulan Juli diperlihatkan pada Tabel 1.

Analisis pergeseran modus bulanan ukuran panjang ikan, menunjukkan bahwa terdapat enam kelompok umur (kohor) dari Juli 2012 hingga Februari 2013 (Gambar 1). Estimasi parameter pertumbuhan Von Bertalanffy untuk spesies ini adalah $L \infty=63,53 \mathrm{~cm}, K=0,63 /$ th dan $t_{0}=-0,21$ tahun mengikuti persamaan sebagai berikut :

$$
L_{t}=63,5\left(1-e^{[0,63(t+0,21)]}\right)
$$

Hubungan umur dan pertumbuhan hasil pengamatan diperlihatkan pada Gambar 2. Hasil penelitian tentang aspek umur, pertumbuhan telah dilakukan oleh beberapa peneliti di perairan yang berbeda. Himpunan temuan tersebut memberikan kisaran indeks yang diturunkan dalam bentuk grafik seperti diperlihatkan pada Gambar 2 .

Mortalitas total $(Z)$ yang diturunkan dari kurva tangkapan yang dilinierkan memberikan hasil sebesar 2,40/ th. (Gambar 3), sedangkan mortalitas alami $(M)$ pada suhu $28^{\circ} \mathrm{C}$ adalah $1,07 /$ th. Dengan menggunakan persamaan empiris (6) diperoleh perkiraan laju kematian akibat 
Tabel 1. Jumlah spesimen, rerata, varians ukuran panjang ikan tongkol komo

Table 1. Number of specimens, mean and variance of length frequency of kawakawa

\begin{tabular}{lrrrrrrrr}
\hline \multicolumn{1}{c}{ Bulan/tahun } & \multicolumn{4}{c}{$\mathbf{2 0 1 2}$} & & & \multicolumn{3}{c}{$\mathbf{2 0 1 3}$} \\
& Juli & Ag & Sep & Okt & Nop & Des & Jan & Feb \\
\hline Jumlah spesimen & 66 & 120 & 180 & 539 & 140 & 120 & 20 & 140 \\
Minimum & 49 & 35 & 31 & 31 & 31 & 31 & 31 & 31 \\
Maximum & 55 & 61 & 57 & 47 & 47 & 49 & 47 & 47 \\
Rerata & 46,2 & 43,8 & 39,8 & 37,2 & 36,8 & 39 & 40,8 & 38,1 \\
Simpang baku & 3,79 & 5,21 & 4,61 & 2.68 & 3,73 & 3.9 & 4,35 & 3,69 \\
\hline
\end{tabular}

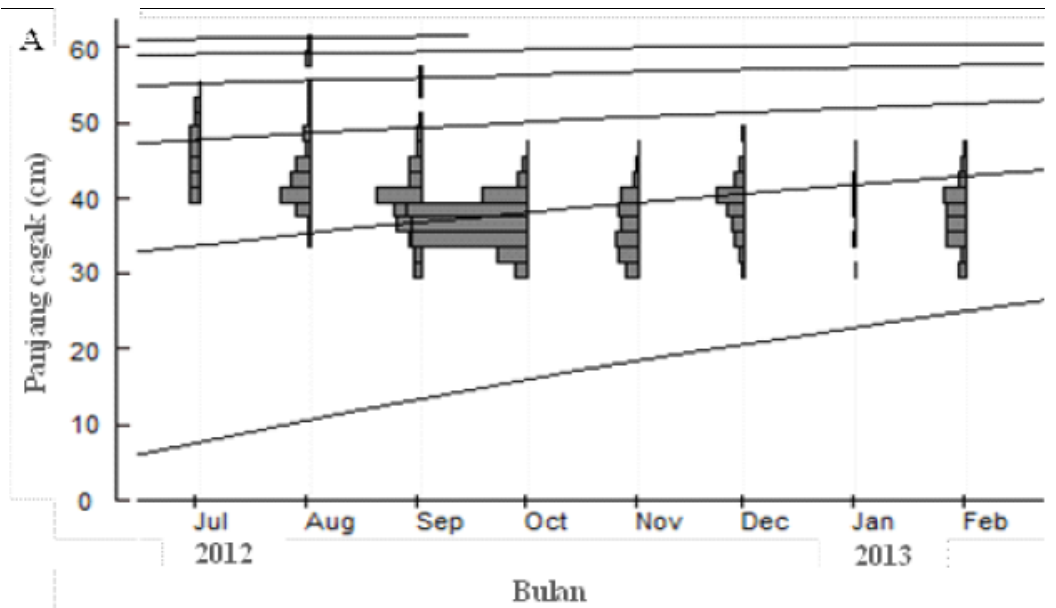

Gambar 1. Kurva pertumbuhan Von Bertalanffy berdasarkan frekuensi panjang $\left(L \infty=63,53 \mathrm{~cm}, K=0,63 /\right.$ th and $t_{0}=-$ 0,21 th).

Figure 1. Von Bertalanffy growth curves based on the length frequencies $\left(L \infty=63.53 \mathrm{~cm}, K=0.63 / y \mathrm{r}\right.$ and $t_{0}=-0.21$ $y r)$.

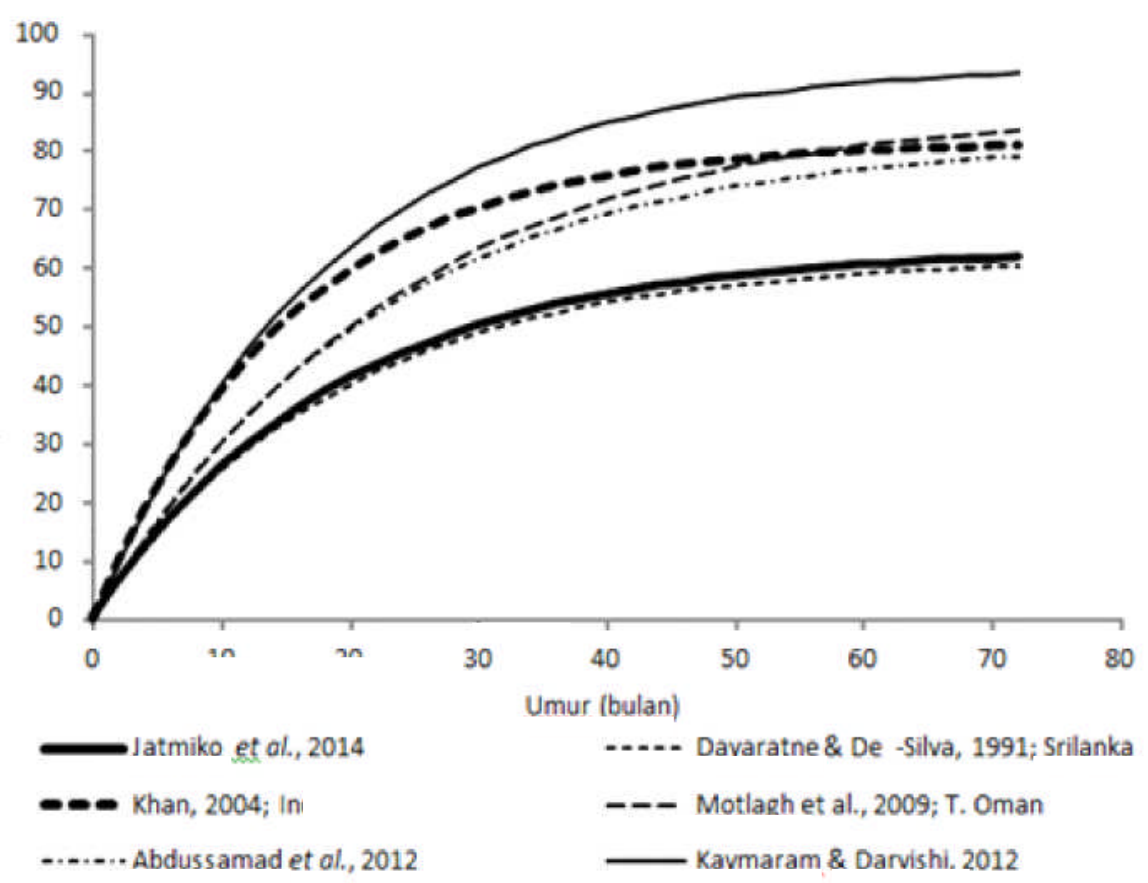

Gambar 2. Hubungan umur dan pertumbuhan E. affinis di beberapa sub perairan Samudera Hindia.

Figure 2. Age and growth relationships of E. affinis from several sub areas of Indian Ocean. 


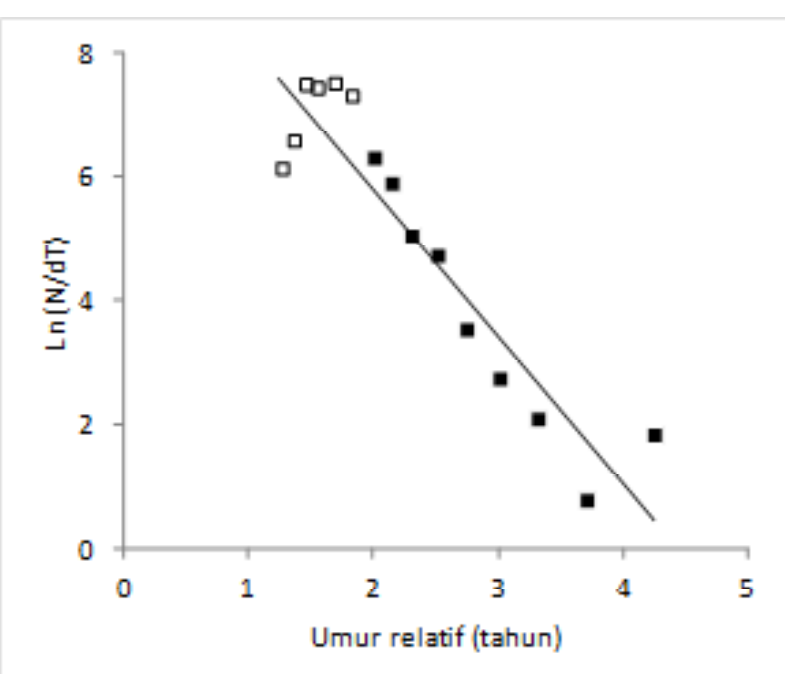

Gambar 3. Estimasi indeks kematian total $(Z)$ berdasarkan kurva hasil tangkapan yang dilinierkan.

Figure 3. Estimation of total mortality $(Z)$ based on linear catch curve.

penangkapan sebesar 1,33/th. Perkiraan tingkat eksploitasi (E) tongkol komo di perairan Barat Sumatera yang diturunkan berdasarkan persamaan (5) memberikan perkiraan nilai $E$ sebesar 0,55.

\section{BAHASAN}

Hasil pengukuran lapang selama kurun waktu penelitian didapatkan bahwa tongkol komo yang tertangkap mempunyai kisaran panjang antara 30-60 cmFL. Dari kisaran panjang tersebut, sebanyak $72 \%$ didominasi oleh kisaran panjang 34 sampai $40 \mathrm{~cm}$. Penelitian lainnya di Pantai Barat Sri Lanka mempunyai kisaran panjang antara 21-74 cm (Dayaratne \& De-Silva, 1991); di Perairan Maharashtra India berkisar 26-73 cm (Khan, 2004) dan 28-64 cm (Abdussamad et al., 2012); di Teluk Persia Oman, 41-85 cm (Motlagh et al., 2009) dan 29- 86 cm (Kaymaram \& Darvishi, 2012).

Analisis panjang asimtotik tongkol komo di Perairan Barat Sumatera ( $L \infty=63,5 \mathrm{cmFL}$ ) cenderung lebih kecil dibandingkan lokasi lainnya di Samudera Hindia, kecuali di Pantai Barat Sri Lanka ( $L \infty=61,5 \mathrm{cmFL})$. Sedangkan koefisien pertumbuhan $(K=0,63 /$ th $)$ lebih tinggi daripada lokasi lainnya di Samudera Hindia, kecuali di perairan Maharashtra India $(K=0,79 /$ th) serta Teluk Persia dan Laut Oman $(K=0,67 /$ th). Perkiraan laju pertumbuhan pada kisaran umur 10-30 bulan (Gambar 2), di perairan Teluk
Oman cenderung lebih tinggi dibandingkan perairan lain di Samudra Hindia. Perbandingan estimasi laju pertumbuhan dan panjang asimtotik diperlihatkan pada tabel Tabel 2.

Perbedaan indeks laju pertumbuhan $(K)$ dan $L \infty$ besar kemungkinan disebabkan oleh struktur data yang terkumpul dan analisis data yang digunakan (Li et al., 1995). Francis (1996) dalam Wang \& Milton (2000) mengemukakan bahwa terjadinya perbedaan tersebut akibat dari anggapan bahwa nilai laju pertumbuhan merupakan indeks yang tetap dan tidak dipengaruhi oleh ketidak pastian, yang dalam kenyataan merupakan suatu peubah sehingga boleh jadi mempunyai ragam, Pengukuran pada waktu dan tempat yang berbeda juga merupakan faktor yang berpengaruh dalam proses analisis karena adanya korelasi yang sangat kuat antara besarnya nilai $L \infty$ dan $K$.

Perkiraan laju kematian alami $(M)$ tongkol komo di Perairan Barat Sumatera sebesar 1,07 cenderung lebih tinggi dari pada lokasi lainnya di Samudera Hindia, kecuali di Perairan Maharashtra India ( $M=1,16 /$ th) (Khan, 2004). Perkiraan laju kematian akibat aktivitas penangkapan $(F)$ memberikan nilai sebesar $F=1,33$ /th berada dalam kondisi sedang dibandingkan lokasi lainnya di Samudera Hindia. Sedangkan laju kematian total $(Z=2,40 /$ th $)$ relatif lebih tinggi dari lokasi lainnya di Samudera hindia, kecuali di Perairan India ( $Z=5,85 /$ th) (Pillai et al., 2002) serta Teluk Persia dan Laut Oman $(Z=2,58 /$ th) (Kaymaram \& Darvishi, 2012).

Perkiraan tingkat exploitasi $(E)$ di perairan barat Sumatera $(E=0,55)$ lebih rendah daripada lokasi lainnya di Samudera Hindia, kecuali di Perairan India $(E=0,8)$ (Pillai et al., 2002) serta Teluk Persia dan Laut Oman $(E=$ 0,65) (Motlagh et al., 2010). Nilai laju eksploitasi tongkol komo, E. affinis di perairan barat Sumatera ini mengindikasikan bahwa tingkat pemanfaatan tongkol komo di Perairan Barat Sumatera berada dalam kondisi moderately exploited. Rangkuman mortalitas dan laju eksploitasi dari berbagai penelitian tongkol komo ( $E$. affinis) di Samudera Hindia dapat dilihat pada Tabel 3. Satu pertimbangan beragamnya laju kematian akibat penangkapan sangat terkait dengan struktur dan sebaran data hasil pengukuran yang diikuti oleh perbedaan ekologi, kondisi fsiologi, ragam mangsa serta tekanan penangkapan (Biswas, 1993 dalam Raesisi et al., 2012). 
Tabel 2. Estimasi parameter pertumbuhan dengan metode frekuensi panjang dari berbagai penelitian tongkol komo (E. affinis) di Samudera Hindia

Table 2. Estimates of growth parameters using length-frequency method from various studies for kawakawa (E. affinis) in Indian Ocean

\begin{tabular}{lccl}
\hline \multicolumn{1}{c}{ Lokasi } & L $(\mathbf{c m})$ & $\begin{array}{c}\boldsymbol{K} \\
(\mathbf{1} / \text { tahun })\end{array}$ & \multicolumn{1}{c}{ Referensi } \\
\hline Pantai Barat Sri Lanka & 61,5 & 0,52 & Dayaratne \& De-Silva, 1991 \\
Perairan Maharashtra India & 81,7 & 0,79 & Khan, 2004 \\
Teluk Persia \& Laut Oman & 87,66 & 0,51 & Motlagh et al., 2009 \\
Perairan India & 81,92 & 0,56 & Abdussamad et al., 2012 \\
Teluk Persia \& Laut Oman & 95,06 & 0,67 & Kaymaram \& Darvishi, 2012 \\
Perairan Barat Sumatera Indonesia & 63,53 & 0,63 & Penelitian ini \\
\hline
\end{tabular}

Tabel 3. Mortalitas dan laju eksploitasi dari berbagai penelitian tongkol komo (E. affinis) di Samudera Hindia Table 3. Mortalities and exploitation rate from various studies for kawakawa (E. affinis) in Indian Ocean

\begin{tabular}{|c|c|c|c|c|c|}
\hline Lokasi & $\begin{array}{c}M \\
\text { (1/tahun) }\end{array}$ & $\begin{array}{c}F \\
\text { (1/tahun) }\end{array}$ & $\begin{array}{c}Z \\
\text { (1/tahun) }\end{array}$ & $\begin{array}{l}E \\
\text { (1/tahun) }\end{array}$ & Referensi \\
\hline Pantai Barat Sri Lanka & 0,44 & 1,45 & 1,89 & 0,24 & Dayaratne \& Silva, 1991 \\
\hline Perairan India & 0,98 & 4,90 & 5,85 & 0,8 & Pillai et al., 2002 \\
\hline Perairan Maharashtra India & 1,16 & - & 2,24 & - & Khan, 2004 \\
\hline Teluk Persia \& Laut Oman & 0,65 & 1,72 & 2,37 & 0,65 & Motlagh et al., 2010 \\
\hline Perairan Veraval India & 0,94 & 0,75 & 1,69 & 0,36 & Ghosh et al., 2010 \\
\hline Perairan India & 0,93 & 0,75 & 1,68 & 0,36 & Rohit et al., 2012 \\
\hline Teluk Persia \& Laut Oman & 0,76 & 1,82 & 2,58 & 0,7 & $\begin{array}{l}\text { Kaymaram \& Darvishi, } \\
2012\end{array}$ \\
\hline Perairan Barat Sumatera Indonesia & 1,07 & 1,33 & 2,40 & 0,55 & Penelitian ini \\
\hline
\end{tabular}

\section{KESIMPULANDANSARAN}

Penelitian ikan tongkol komo (Euthynnus affinis) di Samudera Hindia sebelah barat Sumatera diperoleh laju pertumbuhan $(\mathrm{K})$ sebesar (0,63/tahun, panjang asimptotik $(L \infty)$ sebesar 63,5 cmFL dan umur teoritis pada saat awal $\left(\mathrm{t}_{0}\right)$ sebesar -0,21 tahun. Estimasi laju kematian total $(Z)$ sebesar 2,40/tahun, laju kematian alami $(M)$ sebesar 1,07/ tahun dan laju kematian karena penangkapan $(F)$ sebesar 1,33/tahun dengan tingkat pemanfaatan $(E)$ sebesar 0,55 atau dalam kondisi tingkat pemanfaatan sedang (moderately exploited). 


\section{PERSANTUNAN}

Penelitian ini merupakan kontribusi kegiatan riset perikanan tuna skala kecil T.A. 2012 di Loka Penelitian Perikanan Tuna, Benoa - Bali. Penulis mengucapkan terima kasih kepada Rusjas Mashar dan Musda Sibarani atas bantuannya dalam proses pengumpulan data di Pelabuhan Sibolga, Sumatera Utara.

\section{DAFTAR PUSTAKA}

Abdussamad, E.M., P. Rohit, K.P.S. Koya \& M. Sivadas. 2012. Status and potential of neritic tunas exploited from Indian waters. IOTC Second Working Party on Neritic Tunas, Malaysia.

Collette, B.B. \& C.E. Nauen. 1983. FAO species catalogue. Vol. 2. Scombrids of the world. An annotated and illustrated catalogue of tunas, mackerels, bonitos and related species known to date. Food and Agriculture organization of the United Nations (FAO) Fisheries Synopsis number 125, Volume 2.

Dayaratne, P. \& J. De-Silva. An Assessment of Kawakawa (Euthynnus affinis) Stock on the West Coast of Sri Lanka. Asian Fisheries Science, 4: 219-226.

DPI-NSW (Department of Primary Industry - New South Wales). 2010. Status of Fisheries Resources in NSW, 2008-2009. Viewed 27 May 2013. [www.dpi.nsw.gov.au].

FAO. 2013. FishStat plus: Capture Production 19502010. Diakses pada tanggal 21 Maret 2013, [www.fao.org].

Gayanilo, F.C.Jr., P. Sparre \& D. Pauly. 2005. The FAOICLARM Stock Assessment Tools II (FiSAT II Revised Version). FAO.

Ghosh, S., N.G.K. Pillai \& H.K. Dhokia. 2010. Fishery, population characteristics and yield estimates of coastal tunas at Veraval. Indian. J. Fish. 57(2): 7-13.

Herrera, M. \& L. Pierre. 2009. Status of IOTC databases for neritic tunas. WPDCS. $46 \mathrm{pp}$.

IOTC-WPNT03 2013. Report of the 3rd Session of the IOTC Working Party on Neritic Tunas. Bali, Indonesia, 2-5 July. 75 pp.

Kaymaram, F. \& M. Darvishi. 2012. Growth and mortality parameters of Euthynnus affinis in the northern part of the Persian Gulf and Oman Sea. IOTC Second Working Party on Neritic Tunas, Malaysia.

Khan, M.Z. 2004. Age and growth, mortality and stock assessment of Euthynnus affinis (Cantor) from Maharashtra waters. Indian J. Fish. 51 (2): 209-213.

Li, T. F., C. H. Wang and Y. M. Yeh. 1995. Age and growth of yellowfin tuna influenced by the human exploitation. ACTA Oceanographica Taiwanica. 34 (4): 43-60.

LPPT. 2013. Loka Penelitian Perikanan Tuna, Benoa, Bali: Laporan Tahunan 2012.

Motlagh, S.A.T. 2010. Population biology and assessment of Kawakawa (Euthynnus affinis) in Coastal Waters of the Persian Gulf and Sea of Oman (Hormozgan Province). Iranian Journal of Fisheries Sciences. 9 (2): 315-326.

Patterson, K. 1992. Fisheries for pelagic species: An empirical approach to management targets. Review in Fish Biology and Fisheries. 2 (4): 321-338.

Pauly, D. 1980. On the interrelationship between natural mortality, growth parameters and mean environmental temperature in 175 fish stocks. J. Cons. Int. Expl. Mer. 39: 175-179.

Pauly, D., 1983. Some simple methods for the assessment of tropical fish stocks. FAO Fish. Tech. Pap. 52: 234.

Pillai P.P., N.G.K. Pillai, C. Muthiah, T.M.M. Yohannan, H.M. Kasim, G. Gopakumar, K.P.S. Koya, B.M. Kumar, M. Sivadas, A.K.V. Nasser, U. Ganga, H.K. Dhokia, S. Kemparaju, M.M. Bhaskaran, M.N.K. Elayathu, T.S. Balasubramanian, C. Manimran, V.A Kunjikoya \& T.T.A. Kumar. 2002. Status of exploitation of coastal tunas in the Indian Seas. In: Pillai, N.G.K., N.G. Menon, P.P. Pillai \& U. Ganga (Eds). Management of Scombrid Fisheries. Central Marine Fisheries Research Institute. Kochi. p: 56-61.

Raeisi, H. S. A. Hosseini, S. Y. Paighambari, M. J. Shabni \& S. Kiaalvandi. 2012. Study of natural and fishing mortality and exploitation rate of largehead hairtail, Trichiurus lepturus (Linnaeus, 1758) from the Northern Persian Gulf, Iranian waters . Caspian Journal of Applied Sciences Research. 1 (7): 22-27.

Rohit, P., A. Chellappan, E.M. Abdussamad, K.K. Joshi, K.P.S. Koya, M. Sivadas, S. Ghosh, A.M.M. Rathinam, 
S. Kemparaju, H.K. Dhokia, D. Prakasan, \& N. Beni. 2012. Fishery and bionomics of the little tuna, Euthynnus affinis, exploited from Indian Waters. Indian J. Fish. 59 (3): 33-42.

Sparre, P. \& S.C. Venema. 1998. Introduction to tropical fish stock assessment. Part 1 manual. FAO Fish. Tech. Pap. No. 306.1, Rev.2. 407 p.
Widodo, A.A., F. Satria \& A. Barata. 2012. Catch and Size Distribution of Bullet and Frigate Tuna Caught by Drifting Gillnet in Indian Ocean Based at Cilacap Fishing Port, Indonesia. IOTC-2012-WPNT02-12: 15 pp.

Wang Y-G \& D. A. Milton. 2000. On comparison of growth curves: How do we test whether growth rates differ?. Fish. Bull. 98:874-880. 
Lampiran 1.

(Appendix 1).
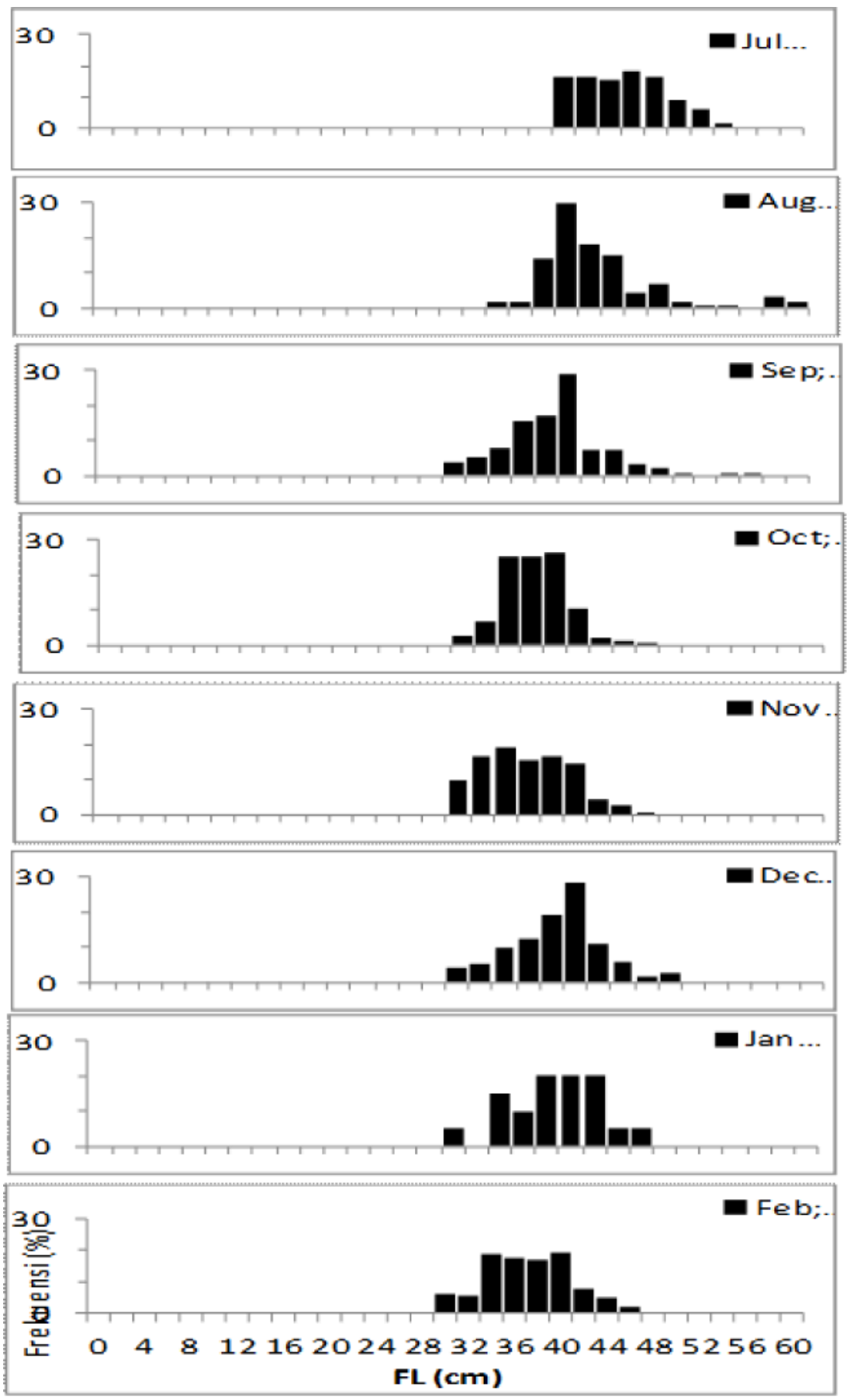

Gambar 1. Sebaran ukuran panjang bulanan ikan tongkol (Euthynnus affinis) di Samudera Hindia sebelah barat Sumatera, Juli 2012 - Februari 2013.

Figure 1. Length frequency distribution of kawakawa (Euthynnus affinis) from Indian Ocean West off Sumatera, July 2012 - February 2013. 